\title{
The spur of the moment: what jazz improvisation tells cognitive science
}

\author{
Steve Torrance ${ }^{1} \cdot$ Frank Schumann $^{2}$ (1)
}

Received: 23 December 2017 / Accepted: 16 March 2018 / Published online: 28 March 2018

(c) The Author(s) 2018

\begin{abstract}
Improvisation is ubiquitous in life. It deserves, we suggest, to occupy a more central role in cognitive science. In the current paper, we take the case of jazz improvisation as a rich model domain from which to explore the nature of improvisation and expertise more generally. We explore the activity of the jazz improviser against the theoretical backdrop of Dreyfus's account of expertise as well as of enactivist and 4E accounts of cognition and action. We argue that enactivist and 4E accounts provide a rich source of insights on improvisation that go beyond Dreyfus's notion of skilled coping, for example, through the central enactivist notion of "sense-making". At the same time, however, we see improvisation also as suggesting an extension of enactivist theory. We see expert improvisers, in music and in life, as walking on a path of open-ended expansion of their mindful experiential relation with their doing. At the heart of an improviser's expertise (and of day-to-day living), we propose, lies a form of "higher-level inner sense-making" that spontaneously creates novel forms of agentive goal-directedness in the moment. Our account thus supplants Dreyfus's idea of the ego-less absorbed expert by that of a mindful (i.e. present in the moment) improviser enacting spontaneous expressions of herself, in music or in life.
\end{abstract}

Keywords Improvisation $\cdot$ Music $\cdot$ Jazz $\cdot$ Music cognition $\cdot$ Expertise $\cdot$ Skills $\cdot$ Enactivism $\cdot$ Embodied cognition $\cdot 4 \mathrm{E}$ cognition $\cdot$ Phenomenology $\cdot$ Sense-making $\cdot$ Temporality $\cdot$ Absorbed coping $\cdot$ Rationality $\cdot$ Mindfulness $\cdot$ Mindlessness

There is a Japanese visual art in which the artist is forced to be spontaneous. He must paint on a thin stretched parchment with a special brush and black water paint in such a way that an unnatural or interrupted stroke will destroy the line or break through the parchment. Erasures or changes are impossible. These artists must practise a particular discipline, that of allowing the idea to express itself in communication with their hands in such a direct way that deliberation cannot interfere.... This conviction that direct deed is the most meaningful reflections, I believe, has

Frank Schumann

Frank.Schumann@gmail.com

Steve Torrance

stevet@sussex.ac.uk

1 Centre for Cognitive Science (COGS), School of Engineering and Informatics, University of Sussex, Falmer, Brighton BN1 9QJ, UK

2 School of Philosophy, Psychology and Language Science, University of Edinburgh, Edinburgh EH8 9AD, UK prompted the evolution of the extremely severe and unique disciplines of the jazz or improvising musician.

Bill Evans, Back Cover notes to the original Long Play release of Kind of Blue (Davis et al. 1959).

Sudnow's detailed description of his acquisition of the skilled hands of a jazz pianist shows the limitations of a cognitivism that thinks that having a skill consists of interiorizing the theory of a domain.

Hubert Dreyfus, Preface to David Sudnow, Ways of the Hand: A Rewritten Account (2001, pp. ix-x).

In 1978, the social anthropologist David Sudnow wrote a detailed autobiographical account, inspired by (among other things) Merleau-Ponty's embodied phenomenology, of how he acquired the expertise of a professional jazz musician. Hubert Dreyfus, in his foreword to the 2001 edition of Sudnow's Ways of the Hand, wrote that jazz piano improvisation provides "a paradigm case of. .. the ways embodied beings acquire the skills of giving order to, or, better, finding order in, our temporally unfolding experience." Dreyfus portrays Sudnow's self-exploration as concretising Merleau-Ponty's work via a detailed exploration of how (in Dreyfus's view) 
the expert jazz-player's hands take over from the jazz-learner's rule-following ego.

The present paper takes the jazz improviser's art as a starting point for the investigation of two, linked, clusters of issues within the philosophy and sciences of mind: focusing on improvisation on the one hand, and skill and mindedness on the other.

1. The first group of issues concerns how the experience of jazz sheds light on the role of improvisation generallynot just in music or art, but in our day to day activities. Improvisation turns out to be a key phenomenon, ubiquitous in our lives. Greater attention to it is, in our view, long overdue. We examine a variety of facets of improvisation, in the context of the thought of Dreyfus and of enactive approaches. We argue that reflective study of jazz improvisation will provide insights into how we improvise our way through life; and this in turn will provide a significant new perspective on embodied cognition and agency.

2. The second group of issues takes jazz piano as a special example of a particular core element of enactive theory as such: skilled proficiency. Dreyfus's interest in Sudnow's description of his journey from novice to expert improviser holds a particular interest in this regard. For Dreyfus it was a specific case to illustrate his wider concerns with skilled activity in general. As is well known, Dreyfus considered the skills of the expert practitioner to exemplify a form of fluent, embodied, "absorbed coping" where mindful attention to the prescriptive rules or canons governing that field had dropped away. However, critical pressure has been put on this idea of skilled "egolessness" in fluent skilled activity from many quarters. We will look at the debate that has grown up, and we will argue that jazz improvisation is a focus case in which an entanglement between mindful and mindless processes is particularly clear. This provides a nuanced intervention in this debate, related to the above new perspective on embodied cognition and agency.

\section{Improvising our way through life}

Jazz improvisation has been both a theoretical and a musical encounter between the two authors of this paper. For some years we have explored improvisation, through periodic conversations in private, and via joint presentations in public with illustrative performances on two pianos. ${ }^{1} \mathrm{We}$

\footnotetext{
1 The presentations have included an informal gathering of academics and musicians in North London; a psychology workshop at the University of Bristol; and an interdisciplinary cognitive science seminar at the University of Sussex.
}

have found a number of fruitful insights from the enactivephenomenological literature (including that of Dreyfus and Sudnow, but also of Francisco Varela, and many others working in the enactive tradition) on the jazz/improvisation domain. For some time we have been working in both directions, both using theoretical reflections to shed light on the jazz performances, and using the performances as a form of commentary on the theoretical issues.

Our work, which is partially confirmatory and partially critical of Dreyfus's and Sudnow's pictures of jazz skillbuilding, will hopefully provide a useful illustration of how the domain of musical improvisation can provide new insights into the nature of skilled action, and to cognitive science in general. We will in particular address:

1. the under-recognized centrality of improvisation to characterizing human expertise;

2. how temporality (at many different levels) conditions the in-the-moment creation of (jazz) improvisation;

3 . the counterpoint between ego-less or mind-less intuitive unwinding, and deliberative, cognized, control in skilled performance, and in particular, in improvisation;

4. the open-ended nature of enactive creation of perceptual worlds for the improviser to improvise in and on, with direct agency and intention.

The present paper thus owes a great debt to the work of Dreyfusian embodied phenomenology — but also to Varelan enactivism. As a label, "enactivism" emerged from Varela and colleagues' landmark 1991 volume (Varela et al. 1991). This book offered powerful critiques of certain assumptions then reigning within classical cognitive science, and particularly the dominance of the computer metaphor in much of the latter. Some of the central elements in the book were pre-figured in the work of Dreyfus, particularly in his What Computers Can't Do (Dreyfus 1972), which assembled some deep weaknesses within classical cognitive science and AI. Over the decades, Dreyfus's insights have been taken up and reworked in new ways (not always with adequate acknowledgement to Dreyfus), by many people, including Varela and those working in the tradition that he inaugurated. ${ }^{2}$

As musicians working on honing our jazz skills, another work by Dreyfus which was of particular interest to us was the critique of cognitivist models of expertise that he co-authored with his brother Stuart (Dreyfus and Dreyfus 1986). The five-stage model of skill acquisition offered in that work, designed principally to exhibit the limitations of computer-based "expert systems", showed a suggestive

\footnotetext{
${ }^{2}$ Many affinities between the innovative approaches of Dreyfus and Varela are discussed in (Winograd and Flores 1986) with particular reference to classical cognitivist approaches to $\mathrm{AI}$ and cognition.
} 
way to understand the progressive growth in a given skill. According to this model, practitioners of a skill will tend to progress from the status of 'novice' to that of 'expert' over five broad stages, where the novice's performance will often start off as intellectualized or theorized, and where true expert performance is characterized by a non-reasoned, intuitive form of skilled action (Dreyfus and Dreyfus 1986, p. 103). We believe that the case of jazz improvisation highlights particular limitations of Dreyfus's model, and that this has implications for understanding the role of skilled action in general-as we shall see later.

We had each of us also been impressed by Sudnow's Ways of the Hand (Sudnow 1978, revised 2001). Working as an ethnomethodologist, alongside pioneering sociologists such as Harold Garfinkel and Harvey Sachs, Sudnow used descriptive observation methods to lay bare implicit rules and assumptions enfolded within various socially structured ways of doing things, including death and dying (Sudnow 1967), and computer gaming (Sudnow 1979). Ways of the Hand logged and explored the detailed stages in the growth of Sudnow's own expertise as a jazz piano improviser. As Dreyfus noted in his 2nd edition preface, Dreyfus saw in Sudnow's account many affinities with his own account of how people develop skills from the halting, self-conscious stabs of the novice to the ego-less flow of the full expert. ${ }^{3}$

In many ways Sudnow's volume acts as a kind of handbook (no pun intended) for many jazz musicians who have read it. This may be partly because the book helps one, as such a developing musical practitioner, to progress in the mastery of one's instrument or genre, and also because the processes he describes may bear some similarity to one's own experiences of progress in skill-building. But also it is perhaps because the book shows how something that often presents to many, on a superficial glance, as a highly informal and "hang-loose" activity, can be framed within rigorous, academic language.

\subsection{Improvisation and enaction}

Enactivism originally arose out the biological work of Francisco Varela and Umberto Maturana, who together propounded a new view of a living organism as an "autopoietic" (literally, "self re-creating") unity operating under principles of internal coherence, rather than as adapting to an independent world. ${ }^{4}$ The autopoietic view which Maturana and Varela propounded, evolved from its original biological

\footnotetext{
${ }^{3}$ Sudnow does not explicitly appeal to the Dreyfus five-stage model. However, a detailed comparison between the Dreyfus and the Sudnow accounts of expertise can be found in Hendriks-Jansen (1996, p. $311 \mathrm{ff})$.

${ }^{4}$ See Maturana and Varela (1986).
}

focus on cells, nervous systems, etc., into a theory of cognition, experience and action-particularly that of humans. As developed by Varela, Thompson and Rosch (in their 1991) it became recast as "enactivism". In our view, enactivism offers a productive vantage point from which to reflect on improvisation, both in jazz and more generally. Two phrases used by core enactivist texts seem particularly fruitful: "Laying down a path in walking; and "Sense-making".

(1) "Laying down a path in walking". This phrase, used as the title to the final chapter of (Varela et al. 1991), may be seen as expressing a central essential strand of the enactivist approach. According to Varela, a human and/or any other biological being "lays down" a world, as one may "lay down a path" as one walks. The phrase also occurs in the title of a 1987 paper by Varela, whose primary focus was biology, but which he also saw as giving a novel cognitive and metaphysical outlook (Varela 1987) ${ }^{5}$. As Varela says of an organism's relation to its world (ibid.): "It is not the mirroring of a world, but the laying down of a world". And as Evan Thompson put it (Thompson 2007, p. 13), the first proposition of the enactive approach is that "living beings are autonomous agents that actively generate and maintain themselves, and thereby also enact or bring forth their own cognitive domains".

The path a walker takes is of course not totally arbitrary, but is rather constrained and shaped by the conditions in the walker's environment, (as well as by the walker's constitution, history, and skills). In a similar way the world an organism knows is not a totally other realm which has to be recovered in perception, but is rather a domain of significances, or a set of possibilities that are made determinate by the organism's actions, and established via the organism's developing skills.

The trope of laying down a path in walking is derived from a celebrated poem of Antonio Machado, a Spanish poet of the late 19th and early twentieth century. Here is an English translation of part of the poem, (quoted in full in Varela 1987):

Wanderer, the road is your footsteps, nothing else; Wanderer, there is no path, you lay down a path in walking.

In walking you lay down a path,

And when turning around you see the road you'll never step on again. ${ }^{6}$

\footnotetext{
5 See also (Thompson 2007, p. 13; Varela et al. 1991 ch. 11).

${ }^{6}$ Caminante, son tus huellas el camino, nada mas; Caminante, no hay camino, se hace camino al andar. Al andar se hace el camino, y al volver la vista atrás se ve la senda que nunca se ha de volver a pisar. A Machado, "Proverbios y cantares" (Machado 1912).
} 
This striking metaphor also captures a key feature of improvisation in jazz, and in other arts that feature extemporized performance. The jazz player is constantly bringing forth novelty which is given existence in the moment of playing. Unlike the musical recitalist who takes a pre-written piece of music and renders in performance, the improvising musician generates the composition, (or elements of the composition) as the audience listens, rather as a street food seller cooks a dish in front of the customer. In the case of a pre-created composition, one can (in principle) edit, or reorder, the composition before it is finally assigned for performance. In case of improvisation there is no chance to edit or correct-one lays down the piece in playing. Machado's lines even capture this unavailability of going back to correct one's past performance: "when turning around you see the road you'll never step on again".

In jazz improvisation, there is, actually, sometimes the possibility of a kind of "post-editing", where, for example, a note or chord that sounds incongruous or unsatisfactory can be recontextualized by the player's (or a co-musician's) offering of further notes that give it more sense as part of a longer sequence. However, Sudnow, for example, refers to such "post-editing" as only an intermediate stage of improvisation that is "very much backward-looking and [only] reparatively forward-going" (Sudnow 1978, p. 56). Yet at the highest levels of freedom, (in line with Machado's wanderer), improvisation — and perhaps life—are inherently forward-going. The jazz pianist Herbie Hancock recalls an incident when playing with Miles Davis in the 1960s. Hancock, as a young, but already highly acclaimed pianist at the time, played a chord that sounded, as he thought, embarrassingly off the mark. To his surprise, Davis just paused for a second, before responding (on his trumpet) with "some notes that made it right. .. with the choice of notes that he made, and the feeling that they had" (Cheadle 2015). ${ }^{7}$

(2) "Sense-making". This phrase, which seems to have originated in a paper by Varela in the early 1980s (see Varela

\footnotetext{
${ }^{7}$ Hancock reflects that, unlike himself until this moment, Davis never judged what happened. Davis did not "hear it as a mistake. $\mathrm{He}$ heard it as something that happened, just an event, that was part of the reality of what was happening at that moment. And he dealt with it." Hancock goes on to say "Since he didn't hear it as a mistake, he felt that it was his responsibility to find something that fit. And he was able to do that."Hancock recalls that in reflecting on this, he learned a central lesson not only about good improvisation in music, but also about life: "We can look for the world to be as [we] would like it to be. But the important thing is that we grow. And the only way we can grow is to have a mind that is open enough to experience situations as they are and turn them into medicine. . Take whatever situation you have and make something constructive with it. That is what I learned in that situation from Miles"(Cheadle 2015). Similarly to jazz, an open, non-judgmental mindset is also central to other forms of improvisation such as improvisational theatre (Johnstone 1979).
}

1984), is also one that Varela (and Thompson) saw as central to what later became known as the enactive approach. As Thompson puts it (2007), "the nervous system does not process information in the computationalist sense, but creates meaning". Looked at in terms of a biological organism, sense-making can be seen as a kind of interplay between the maintenance of self-identity by an organism and the world with which it maintains a sensorimotor coupling. The organism's environment is a world of elements that matter to the organism, as assisting or threatening the latter's self-maintenance. So the environment is not a neutral, exterior world but a world already interpreted as an array of self-generated significances. It is perhaps not too far a stretch to say that the continual unfolding of the process of an organism's meaning-making encounter with its environment is like an improvising jazz musician generating musical responses that make sense in the context of her fellow players' (and her own) previous musical "moves".

The jazz parallel further suggests an extension of the idea of sense-making from a process enacted by an individual agent, into the inter-agential realm-as an ongoing interplay of mutual significances between members of a social group. Hanne De Jaegher and Ezequiel Di Paolo have described interactive encounters between two or more humans as a process of "participatory sense-making" (De Jaegher and Di Paolo 2007). ${ }^{8}$ The idea of mutual sense-making involving multiple actors yields a powerful, recursive picture of the complex reflections and interactions that occur in a group of people attending to each other's attention. To take the dyadic case for the sake of simplicity: if two agents each attend to each other, each attends to the other, but also to the other's attention, and to the other's attention to their attention to the other's attention, .... and so on. A complex nesting of relationships is thus set up-rather as two mirrors, held together, may generate a "tunnel" of images of reflections within reflections.

Obviously, the interpersonal relationships between jazz players in any given performance are, like any cultural or cognitive activity, shaped by the local social contexts within which any such performance takes place, and the broader socio-cultural history of the genre. The improvisatory nature of jazz performance makes it, we believe, particularly suited to be a model for a broader range of cognitive activity. This point has been well articulated by Michael Tomasello, who is perhaps one of only a few cognitive scientists to make an explicit connection between jazz improvisation and

\footnotetext{
${ }^{8}$ For a specific application of participatory sense-making to music, see (Schiavio and De Jaegher 2017). The application of sense-making to human interaction has also been studied under the label "interenaction", see (Colombetti and Torrance 2009; Schiavio 2014; Schiavio and Cummins 2015; Torrance and Froese 2011).
} 
cognition in general. Critiquing traditional in-the-head models of thinking, Tomasello writes:

“.... [F]or humans, thinking is like a jazz musician improvising a novel riff in the privacy of his own room. It is a solitary activity all right, but on an instrument made by others for that general purpose, after years of playing with and learning from other practitioners, in a musical genre with a rich history of legendary riffs, for an imagined audience of jazz aficionados. Human thinking is individual improvisation enmeshed in a sociocultural matrix." (Tomasello 2014, p. 1).

There are, of course, a number of other ways in which enactivist and allied approaches can be deployed to shed light on musical activity and improvisation in particularfor example-theoretical concepts such as autonomy, environmental embedding, dynamical embodiment, perceptionas-action, and so on, all lend themselves to being applied to jazz and other improvisatory art. Some of these concepts, and the bodies of theory that lay behind them, have been grouped together under the label "4E cognition"- an abbreviated way of summing up mind, cognition and action as embodied, embedded, extended, and enactive (Newen et al. Forthcoming; Menary 2010; Rowlands 2010). There have been many useful suggestions of how improvisation can be theorized in terms of the 4Es or Enactive framework. ${ }^{9}$

Some interesting conclusions may be drawn from these observations on the relation between improvisation and the enactive approach (and related approaches) to cognition and action. First, enactivism may offer a fruitful theoretical backdrop for understanding improvisation in jazz and other performance arts. Second, the case of improvisation (not just in jazz but more generally) may, in turn, offer a source for powerful ways of deepening enactive theory and other phenomenological and 4E approaches. Third, as enactivism is a theory with general application to agency, cognition and, indeed, life, it may thus be time for improvisation and related concepts to be promoted to taking on a more central place within cognitive science research per se. Perhaps, if such a promotion had taken place some decades ago, its subject area might have been rather different.

\subsection{Improvisation and embodiment}

In sum, we would suggest that jazz, given its improvisatory nature, would be a good starting point for an alternatively reconstituted science of mind-where "mind", as seen from this vantage-point, obviously includes a lot more than merely "cognition". One obvious reason for that is that

\footnotetext{
9 See, for example, (Goldman 2013; Iyer 2004; van der Schyff 2017; Walton et al. 2015).
}

jazz, and music-making in general, for all their cognitive aspects, are highly embodied - the "hand" of the pianist, to use Sudnow's key term; the mouth and breath of the flute or trumpet-player; the throat and lungs of the vocalist; but also the way the whole body of the player moves-whether seated at the keyboard or drum kit or standing holding the bass or blowing the sax. Music is embodied because of the interactive, unified way in which the musician is linked to her instrument. It is embodied also in virtue of the nature of our response to the music, whether as player or listener: jazz audiences, in particular, tend to explicitly register their listening through physical signals such as clapping, foot-stomping, whooping, etc.; players often make similar gestures in their performance. Again, as in all musicianship, jazz performance is about physical mastery of the skill of playing the instrument. Developing skillful musical agency involves assuming and assimilating various embodied stances, postures and movements (Bowman 2004). This holds for improvisation in particular. In his phenomenological report about learning how to improvise, David Sudnow relates his most substantial developmental transition towards improvisation to working on timing and temporal stances with his body after observing how Jimmy Rowles (a pianist described as a "musician's musician") moved on the bench (Sudnow 1978, p. $81 \mathrm{ff}$ ).

Being so emblematically embodied, jazz performance, apart from its intensively physical nature, is also often affectively highly charged, and experientially vivid. As such, it incorporates many features of embodied activity that are marginalized within the traditional cognitive scientists. Indeed, jazz may present an embodied, but also cultural and social, activity that incorporates many aspects of what happens when we are spontaneous in life (Corea 2016; Mercer 2007; NYU Steinhardt Jazz Studies 2014). However, with jazz improvisation the abilities of players span a wide spectrum of performance levels. Thus jazz presents ample opportunities to study embodied improvisation at multiple levels of proficiency, yielding insights into how such skills develop. ${ }^{10}$

Embodiment is, of course, one of the key terms grouped under the heading "4E cognition". A large subset of the cognitive science research that takes embodiment seriously focuses on how our embodied interaction with the world can be productively discussed in terms of the dynamical progression in time of our bodily activity. The temporal flow of our embodied action plays a central role in understanding the nature of improvisation in performance. Temporality is

\footnotetext{
10 There has been a considerable literature discussing embodiment in relation to music in general. See, for example, (Krueger 2014, 2011; Laroche et al. 2014; Laroche and Kaddouch 2014; Linson \& Clarke, 2017; Loaiza 2016; Matyja and Shiavio 2013; Schiavio and De Jaegher 2017; Schiavio et al. 2014, 2017).
} 
a feature which complements the intensive physicality of jazz-making. We thus now move on to examining how jazzmaking, and improvisation more generally, is temporally enmeshed in a multiplicity of individual, social and cultural processes.

\subsection{Improvisation and temporality}

\subsubsection{The spur of the moment}

The most obvious way in which the notion of improvisation relates to temporality is in terms of its etymology: the word "improvise" is derived from the Latin Improvisus, or "unforeseen". The term suggests an implicit contrast between performing a task "in the present tense", as it were, without much prior preparation; and executing a task which has been pre-planned or pre-scripted, where steps in the task-fulfilment involve either reading off from a notated set of directions or working from a previously internalized set of rules. Much musical performance may, of course, be unforeseen by, or surprising to, members of the audience ${ }^{11}$ —but improvised music is often unforeseen (or often has elements that are unforeseen) even by the performer, not to mention the other players.

We shall see later, however, that it is a mistake to link the "improvised" too closely with the "unprepared." In fact a considerable amount of improvised performance is extensively planned in advance-and much jazz performance includes, or is indeed mainly comprised of, playing from pre-written sheet music. ${ }^{12}$ Even in most contemporary jazz performance, where musicians may improvise singly or collectively over extended stretches, there will usually be pre-arranged structural constraints (for example, a prior agreement that a specific passage of improvisation should last for a fixed number of repetitions of a particular chord progression, or a fixed number of bars, etc., or that one of the ensemble should give a specific signal when it is time for a pre-composed section to be resumed).

But a good deal of the surprise and edge that is associated with jazz playing (see below for some commentary on this from musicians) comes from the fact that much of what is being produced is as much "in the moment" to the players as it is to the audience. So there are of course some notable free jazz performers or groups, where improvisation is the

\footnotetext{
11 A celebrated example within the "classical" canon was the first performance of Stravinsky's Rite of Spring, in Paris, on 29 May 1913, which provoked a riot among outraged audience-members.

12 So, for example, many of the great jazz performances of big bands led by Duke Ellington, Count Basie and so on, allowed only very short improvised solo sections, performed by selected members of the band.
}

central determinant of what happens, and almost all pre-set parameters drop out of the performance. ${ }^{13}$

Another way of characterizing the unforeseen nature of (much) jazz is to say that certain key aspects of the composition take place in the time of the performance, rather than beforehand, as is generally the case with music prepared by a classical composer. So, while there may be much preparation in advance for any given jazz piece, much of the composition-at least during solo, or "group-blowing", passages, takes place at the time that the music is "consumed" by the audience. So a distinguishing feature of improvisation in jazz, and of improvised performance more generally, is that preparation-time significantly overlaps with, or bleeds into, performance-time.

A number of jazz musicians have commented on this inthe-moment aspect of jazz improvisation. When asked for a brief characterization of improvised music versus music composed before its performance, the jazz saxophonist Steve Lacy summed up the contrast as follows:

"In fifteen seconds the difference between composition and improvisation is that in composition you have all the time you want to decide what to say in fifteen seconds, while in improvisation you have fifteen seconds." [Quoted in "A Passion for Jazz: Music History and Education," 2017 (online)].

More pithily, the pianist Bill Evans has said:

Jazz is the process of making one minute's music in one minute's time

(Quoted in Cavrell 1966, The Creative Process and Self-Teaching_film available on YouTube).

Jason Rebello, a prominent UK jazz pianist, has commented as follows on the precarious, in-the-moment, nature of jazz performance, which often requires split-second reaction and response:

It's the unpredictability of life that drew me to jazz or improvising in the first place. The ability to sit there with no idea of what is going to happen next and to trust that whatever does happen will be ok, is one of the most vital qualities needed to improvise well. One thing I have found over the years, is that thinking does not really help the improvising process. If anything, it hinders it as it is too slow and clunky to be of use in the moment of a rapidly changing musical landscape....

\footnotetext{
${ }^{13}$ Historic examples of free jazz can be found in much of the work of Ornette Coleman, Cecil Taylor, Charles Mingus, Eric Dolphy, John Coltrane, and so on.
} 
Fig. 1 Improvisation in jazz: a spectrum

\section{CONSERVATIVE / SAFE END}

- keeping close to the original theme (or "head");

- $\quad$ adding stock ornamentations to melody;

- using standard chord-variations;

- using standard rhythmic variations;

- use of "library" patterns; quoting other tunes or rehearsed phrases;

- reliance on previous innovations by other musicians;

- focus on observing jazz conventions "correct" jazz;

- emphasis on cognitive control;

- relatively low arousal state

[Examples: Chet Baker \& Bill Evans: The Legendary Sessions (1959); Count Basie, Duke Ellington, Louis Armstrong; Errol Garner]

\section{RADICAL / RISKY END}

- radical and full departures from conventional tempi, chords, theme, etc.;

- exploring unusual sounds or effects from instrument;

- $\quad$ using instrument as sound producer rather than (just) as music device;

- using 'error' to create new possibilities;

- maintaining edginess, rawness;

- working off the expressing affective state as well as musical content;

- emphasis on intuitive unfolding;

- high arousal state

[Examples: Ornette Coleman: The Shape of Jazz to Come (1959), Cecil Taylor, Andrew Hill, Evan Parker]
(Rebello, private communication ${ }^{14}$ ).

\subsubsection{Before the moment}

While we have stressed the "in-the-moment" character of improvised jazz, it is important to stress that for any improvised jazz work, much preparation for the moment of performance will need to have been done in advance. Indeed a well-trained and well-rehearsed jazz musician will spend many hours in a week learning, and crucially, mastering, tonal and rhythmical relations in various harmonic and rhythmic systems, to exploit this practical expertise fluently in real-time performance. So there is something a little misleading in the quotations above, as they both make it sound (when taken in isolation) as though the jazz is simply about just turning up and playing. In fact, as with any performance art-form, there will be a substantial pre-performance period devoted to skill-building, and to preparation for the specifics of any given performance.

This misconception is sometimes built into the way improvisation is conceived or defined. Thus one dictionary website gives the following as one of its two definitions of improvise: "to perform or make quickly from materials and sources available, without previous planning." (https:// www.collinsdictionary.com—emphasis added.) Again, dictionary.com defines improvisation as "the art or act of ...

\footnotetext{
14 These remarks were given as part of some comments made by Rebello to an early sketch of our ideas on improvisation.
}

composing, uttering, executing or arranging anything, without previous preparation." (Emphasis added.) However, as we have pointed out above, much improvised jazz is meticulously prepared beforehand.

It may surprise the newcomer to jazz to hear that improvised elements in jazz may contain such strongly pre-fashioned features. Is not the whole point of improvisation to "make it up as you go along", to "let it all hang out"? In fact, the picture is a lot more complicated: there are many different aspects to improvised jazz, many or most of which will be addressed in offline rehearsal to make the actual performance possible. Some of these aspects will involve relatively restrained variations on the performed material; others will involve some rather more radical ways of generating (or searching for) novelty.

A linked point to this is that improvisatory features in jazz performance can usefully be thought of as lying on a spectrum from conservative to radical, or from "safe" to "risky". At the more conservative end, the novelties that are generated in the performative moment may consist of a relatively limited set of variations along melodic, chordal, tonal, rhythmic and other parameters-although such performances will be likely to be much more than straightforward recitals as if from musical scores on the page, and will still exhibit considerable amounts of spontaneity. At the more radical or "free form" end, one will tend to find a greater emphasis on more extreme kinds of novelty or exploration that may renounce any constraints during the time-frame of the performance itself. (See Fig. 1.) 
In the middle ground between both extremes, one can find improvisation that strives to go beyond pure variations of existing structures without giving up on form entirely. Thus players may extemporize some dimensions of prior structure, such as the spontaneous re-harmonization of the harmonic progression of a tune while remaining faithful to other features such as the tune's original melody. On another level of novelty, improvisers occupying this middle ground may depart from standard roles in performance, such as soloist versus accompanist, in favour of equally co-leading roles for all. Notable pioneers in the latter were the musicians in the first trio led by pianist Bill Evans ${ }^{15}$ (Berendt 1982).

Yet common to all accomplished jazz musicians, even to those whose preference is to play at the radical or risky end of the spectrum, is that they will have put an prodigious amount of prior effort and time into rigorous off-stage preparation-both in isolation and with fellow-performers-of the many skills necessary to deliver fluent and convincing-as well as courageous and fulfilling-improvised performances.

This is well expressed in an interview conducted by Japanese writer and Buddhist philosopher Daisaku Ikeda with Herbie Hancock and Wayne Shorter, two of the world's leading jazz musicians. This is summarized by Ikeda as follows:

"Improvisation embodies the power to create value freely from an instantaneous encounter....At the same time, polishing the power of improvisation to its true brilliance demands constant, unseen effort. As is only considerate and a sign of good faith, I prepare for dialogues by thoroughly studying the person with whom I will be talking." (Ikeda et al. 2006, emphasis added).

\subsubsection{Other temporal aspects}

So far we have looked at temporality in improvisation in one broad way-in terms of the contrast between what happens in the before-phase of a performance-when a work is being prepared, composed, rehearsed, etc.- and the now-phase, when the work is being performed to an audience. Improvised jazz (and improvised art in general) has what appears to be a special property: the two phases at least partly, and maybe significantly, overlap. We conjecture that this makes an important contribution to what people often describe as the 'immediacy' of jazz.

However, it is worth noting that there are many other ways in which improvised music displays time-related features. For example:

\footnotetext{
15 The trio comprised of Evans, bassist Scott LaFaro and drummer Paul Motian. See, for example, their album Sunday at the Village Vanguard (1961).
}

- Multiple scales of temporality in performance.

Because of the way music performances unfold in time, it is natural to discuss the characteristics of such performances in terms of various temporal features (which may vary according to period, region, genre, and so on). In jazz the most usual time-related features include time-signature, tempo, rhythm, syncopation; simultaneity and sequentiality (e.g. chords versus arpeggios); and so on. These features are largely shared with non-improvised music performance.

- Coordination/interaction dynamics within the temporal flow:

a. intra-player coordination: any musician's skill will involve coordination along a number of elements inside the player's body/brain boundary: for example, between hand and hand; hand and ear; between the player's body and her instrument; and, where two or more players are performing,

b. inter-player coordination: there will be various kinds of interaction between players that take place in a nearinstantaneous or tightly sequential fashion. There are many analogies between temporal patterns in joint music-making and in conversation. For example in joint speech one has turn-taking modes of talking/listening, and overlapping or collective speech patterns (such as heated argument, verbal expression during love-making, by crowds at sports matches, and so on). Similar variations occur in joint music-making.

- Cognitive processing in improvisation: fast versus slow/ mindless versus mindful performance:

Improvised musical performance (as much other human action) is characterized by a tension between "fast" and "slow" thinking processes: in-the-moment composition often requires rapid, pre-conscious, intuitive processing, while players will also need to monitor and control performance using slower, conscious, deliberative or mindfullyengaged processing. ${ }^{16}$ Much of the skill of the improviser consists of knowing how to mediate between these two speeds of output. (We will return to this point later, when discussing Dreyfus's account of expert cognition and skillful embodied coping.)

\footnotetext{
${ }^{16}$ Compare Jason Rebello's remark, quoted earlier, about (deliberative) thinking-_... [it] does not really help the improvising process. If anything, it hinders it as it is too slow and clunky to be of use in the moment of a rapidly changing musical landscape.
} 
- Historicity and cultural embedding versus immediacy.

On a markedly longer timescale, it is obvious that much (most?) artistic production takes place within a historical tradition. Again there is another tension here: on the one hand there may be a more or less self-conscious acknowledgement by the artist of the past legacy of one's particular genre (stretching back years or centuries): this may generate constraints to which the artist more or less agrees to conform (for example the 12 bar blues pattern). In contrast (and again especially in improvised art) there may be a kind of "now-ness" to the playing, that departs from the traditions governing one's idiom-possibly critiquing or challenging that tradition in various ways (self-styled "avant-garde" jazz takes such challenge as central).

\subsection{The ubiquity of improvisation}

Within Western academic musical communities, much discourse on music and teaching of music tends to view improvisatory art as unusual or anomalous, as a mode of musical performance that deviates from the normality of recitative music. So the musical skills that are taught academically are dominated by mastery of correct reading and playing from notated works by composers of distinction. It is not uncommon to find people who have been "classically" trained to find it very challenging to break the spell of the printed manuscript when invited to experiment with musical improvisation. Within such a mind-set, jazz, and improvisation in general, are considered to be a special case within music. However, in fact many musical traditions besides jazz treat improvisational skills as central to their genre. Further, it appears that many composers and recitalists within the Western classical tradition in earlier centuries appear to have used improvisation of different kinds quite frequently during their performances. ${ }^{17}$ Today European and North American music departments and conservatoires are much more likely to include improvisation as a core part of the curriculum than they were, say, 40 years ago.

So improvisation seems, perhaps unfairly, to occupy a rather anomalous, or specialist, position within many views of music production. Yet when we turn to improvisation in a wider context, the reverse may well be the case. How far,

\footnotetext{
17 Bach's Musical Offering, based on a brief "Royal Theme" devised by the Prussian Emperor Frederick II, started out, so the story goes, as a three-part fugue extemporized by Bach, at Frederick's request, in his palace in Potsdam in 1747 (see, e.g., Milka 2015). Some professional music writers are now becoming more aware that the absence of improvisation in standard contemporary classical music performances is a lack rather than a virtue-see for example Clive Brown, "We're playing classical music all wrong-composers wanted us to improvise" (Brown 2015).
}

then, does the phenomenon of improvisation extend outside the artistic sphere? We could define improvisation very narrowly so that it only exists in art. However, that hardly accords with common usage, or with the strong intuition that something very much like what is exhibited within the jazz sphere occurs widely outside art.

The suggestion could indeed be made that improvisation is ubiquitous-maybe even the norm in life. Take walking around a town, for example. Most of the time, one might say, we "just walk." But many aspects of the walk are spontaneous and improvised. We invent many things as we go. Do we amble, march or break into a trot? Do we cross the road here, or a bit further on? And so with many action-types in life: talking, eating, sleeping, washing, sport, and play. Humans improvise when making love, when fighting, and when giving birth — and there are perhaps improvisatory elements even in being born or dying. So, it would seem that, in much of life, we extemporize more frequently than we follow a script. As jazz pianist Chick Corea has put it: improvisation is not something special, but "living, just something natural." ${ }^{18}$ And, as Walton et al. write (2015): "You can never step into the same river twice, never play the exact same game of soccer, never navigate your car through the exact same highway traffic, or cook your favorite meal the exact same way ...".

These considerations raise the further question: if improvisation is ubiquitous in our lives then surely it deserves to be discussed more centrally in cognitive science or in psychology? Some areas of cognitive science - for example-those that revolve around notions such as situated action/cognition-may be thought to be particularly amenable to giving improvisation special status.

An early study in situated cognitive science (specifically of AI planning), which foregrounds improvisation is Agre and Chapman (1987). ${ }^{19}$ They suggest that the immediacy of real life makes the techniques for constructing action-plans in classical AI systems inappropriate (they dub this "capital P Planning"). In what they call "lower-case-p planning", by contrast, the rules or recipes are relatively sketchy and the execution continually involves "rearrangement, interpolation, disambiguation, and substitution" ( $\mathrm{p} 268$ ). As they put it: "[L[ife is a continual improvisation, a matter of deciding what to do now based on how the world is now.. . Life is fired at you point blank: when the rock you step on pivots

\footnotetext{
18 Improvisation Piano Exercises with Chick Corea (YouTube video), (Corea 2016). See also Jordanous and Keller (2012), Linson and Clarke (2017) and (Higgins and Mantie 2013; Lewis 2009; Miller and Iyer 2010; Nachmanovitch 1990) cited in Van Der Schyff (2017) p. 1.

${ }^{19}$ See Linson et al. (2015) for a more recent subsumption architectural approach to improvisation.
} 
unexpectedly, you have only milliseconds to act." (see also Agre 1988; Agre and Chapman 1987, p. 268).

These remarks harmonize with our earlier observations concerning the ways in which key notions within the enactive tradition (laying down a path in walking; sense-making) already seem to suggest that improvisation is a general feature of lived action, rather than a side-show, and for that reason should be put into the foreground of a considered account of cognition and action. Dylan Van Der Schyff, writing in the field of music education, has similarly argued that improvisation is central, not merely to music, but to the understanding of human action and knowledge in general, seeing it as reflecting "the adaptive and relational nature of human meaning, and world making more generally" (Van Der Schyff 2017, p. 1). Van Der Schyff goes on to point out that much of the writing in the enactive (and, more generally, 4Es) tradition within cognitive science may be considered as compatible with an outlook which regards lived activity as fundamentally improvisational in character. Indeed, Van Der Schyff entitles an important section of his paper "Cognition as embodied, embedded, enactive and extended and ... improvised." (van der Schyff 2017, pp. 9-11). We applaud this suggestion that improvisation should be given a higher profile within studies of cognition and lived action, and that the notion can be used to complement insights gained within enactive and related approaches. ${ }^{20}$ (It was suggested by a referee of our paper, that, in place of "improvised" one could rather add a 5th E, namely "extemporised" !).

\section{What improvisers do}

As a contribution to the role of improvisation within this wider discussion of cognitive science, ${ }^{21}$ we aim to provide a first step in considering how the character of the accomplished improvisational musician's skill may help in deepening our understanding of lived action and cognition in general. For this, we first return to considering questions raised by Dreyfus about the nature of expert activity, which we see as a basis of improvisatory activity. Particularly, as touched on earlier in our discussion, we will focus on what he called "mindless, absorbed coping", as well as on phenomenological accounts of expertise, both in practice and development. Focusing on improvisation, a key claim we will then make is that improvisational expertise in particular involves a non-deliberative, directive mental presence in the moment, both entangled with and extending the "mindless",

\footnotetext{
20 The main focus of Van Der Schyff's paper, we should note, is to point to new directions for the understanding of music, and more specifically, of music education, rather than to make an intervention within cognitive science or theory of action.

${ }^{21}$ See Linson and Clarke (2017) for a recent ecological/4E account of minimal system requirements for improvisation.
}

absorbed coping that Dreyfus and others have put at the centre of their accounts.

\subsection{Dreyfus on skilled expertise}

Dreyfus has forcefully argued for expertly skilled coping as a basis for human cognition. His argument rests on a critique of classical cognitivism that is shared by enactivism and other theories stressing embodiment. According to classical AI-influenced theories of cognition, as seen by Dreyfus, expertise can be understood as an intellectualized, mastery of rules which are situation-independent, by a mind which is characterized in terms of conceptual understanding, or analytical rationality. On his view such rules are ill equipped for the holistic forms of understanding that he sees as central to natural human cognition, and thus, by extension, also to improvisatory activity.

Dreyfus considered rules of that sort to be perhaps applicable to certain artificial micro-domains, but inadequate for the vast majority of real-world contexts of human life, since real-world contexts are situation-dependent- that is, embedded in the agent's holistic real-world activity. Expertise, on his account, is exercised for the most part in an embodied, non-conceptual-and hence "a-rational" — way rather than through explicit rule-following.

As we saw earlier, a key notion of Dreyfus's thinking is that humans develop such a form of practical wisdom in a staged developmental path, where only the last stage exhibits what Dreyfus considers true "a-rational", embodied expert practice. Prior stages of learning expertise may actually involve practice that is relatively intellectualized and rationalistic. However, what the developing expert does is not merely to "interiorize a set of rules". Rule-based practice is, rather, a scaffold that bootstraps a different form of learning that is then made properly embodied and contextual (Dreyfus 2005; Dreyfus and Dreyfus 1986). As an example that illustrates Dreyfus's account, consider a learning golfer, whose approach to a making a swing involves following, in a more or less conscious or deliberative fashion, a set of procedures for how to stand, grip the club, focus visual attention, follow through, etc.; whereas an accomplished golfer will execute such bodily and attentional aspects of the shot in a single, effortless flow, with little, if any, exercise of conscious mind. Similarly, under Dreyfus's account, a novice jazz musician may follow a collection of improvisational routines, more or less consciously constructed to produce the desired musical result; ${ }^{22}$ whereas the playing of a seasoned

\footnotetext{
22 There are, however, more enactive models of music education being developed in which musical material is introduced via a less cognitivist approach (Laroche and Kaddouch 2014; Schiavio and Cummins 2015; van der Schyff 2017; van der Schyff and Schiavio 2015) seeking to build a more dynamic, exploratory fashion that is perhaps closer to natural ontogenetic development (Spencer et al. 2006).
} 
soloist will tend to involve a fluent set of notes, without any detached awareness, in the moment of execution, of how the different component features that make up the playing have been selected, or fit together. Veteran jazz pianist and educator Kenny Werner speaks of attaining "effortless mastery" of an element of music as occurring when an improviser "owns" the element to a degree where he is able to use it without giving thought to its execution (Werner 1996).

In a little more detail: (1) When learning a novel skill for which she lacks any prior contextual understanding a "novice" may begin her learning from a set of context-free rules that allow her to execute a range of actions in the domain, prior to any sense-making activity being possible. (2) Yet soon, as an "advanced beginner", she will start to see some situational features that allow some first contextual distinctions. (3) At the stage of a "competent performer" she will have accumulated an overwhelming number of both rules and contextual distinctions, and then is presented with the necessity to make decisions among the possible alternatives that may apply. By having a choice, she enters a situation where her decisions may be more or less successful. From affective connotations related to perceived successes and failures, a notion of "significance" emerges. Her action choices now begin to matter to her. (4) Having a notion of significance, as a now "proficient performer," sensations of risk and fulfilment begin to function as drivers for a new form of learning that transitions fully away from rule application to a learning of properly situational discriminations and salient goals. (5) Last, as an "expert performer," she has acquired a rich repertoire both of such contextual "sensations about," and of contextual "actions within," the domain. She sees in any given situation what can be or needs to be done, and immediately knows how to do it. Dreyfus has forcefully defended the view that at this point, the expert responds to the "full concrete situation," and becomes absorbed in her "embodied coping", such that mindful attention would only disrupt the process.

However, there have been extensive arguments both for and against in particular this last point, the emphasis on mindless coping. We will now consider these arguments, drawing in particular on recent reports on the real-world phenomenology of expert action, as well as on enactive theory. The discussion will take as its context our overarching theme of (jazz) improvisation, which provides a distinctive perspective on this debate.

\subsection{Slow versus fast thinking-system 1 and system 2}

Dreyfus's philosophical view on mindless embodied coping fits in well with "dual process" accounts of human cognition (see, for example Daniel Kahnemann 2011; Stanovich 2011). For Kahneman, expert performance that "flows" in the moment is supported by what he called "System 1", a form of cognitive operation that is much akin to Dreyfus's "immediate coping" in that it is rapid, intuitive, automatic, and pre-conscious. System 2, on the other hand is slower, reflective, and method-based. [Compare, for example, entering in your password in a fluent, routine way (system 1), with typing it in more carefully and with more alertness, when a couple of previous rapid shots have failed (system 2)]. Following Dreyfus, one might say that it is only prior preparation in the early stages of expertise development that rely on a system 2 style of operation (see also Ericsson et al. 1993), characterized by what Dreyfus would term a situation-independent and domain-general form of rational thinking. But a system 1 style of operation will dominate the fluent, absorbed, "mindless" action of the accomplished expert (see also Beilock and Carr 2004; Dietrich 2004).

Dual-process theory is often discussed primarily in terms of "in-the-head" processing —-hence the title of Kahneman's book: Fast and Slow Thinking. But clearly it also appears to apply to embodied activity - and in particular to musical performance of varying levels of skill. Dreyfus would reject the idea that skilled activity (à la system 1) involves anything that could be called "thinking" at all. Also Dreyfus's account would appear to be readily applicable to a wide variety of cases which do not lie on a novice-expert spectrumcases such as play, chatting, food-preparation, dressing, etc., which are common in our lives, and where, as we observed above, improvisation seems to be ubiquitous. ${ }^{23}$

\subsection{Debating mindfulness and rationality}

However, how mindless is an experts embodied action? Recent investigations of the real-world phenomenology of skilled performance have put the notion of absorbed coping (as well as a simple dichotomizing of system 1 and system 2) into question. Here we will argue that improvisation may be a mindful activity. This will put pressure on such an all too stark division.

Dreyfus's views have been challenged by many people. One notable example has been the philosopher John McDowell. In a debate with McDowell, initiated by Dreyfus's (2005) presidential address to the American Philosophical Association, Dreyfus depicted McDowell as falling prey to "The Myth of the Pervasiveness of the Mental" (as

\footnotetext{
${ }^{23}$ Even though Dreyfus applies the notion of expertise to the matters of our normal everyday life from childhood on, his model of learning applies largely to the acquisition of specialist skills later in life. However, ontogenetic development may arrive at similar forms of accomplished ability via more embodied and dynamic developmental routes (Oudeyer and Smith 2016; Thelen and Smith 1994).
} 
Dreyfus later called it). ${ }^{24}$ According to this myth, as applied to McDowell's views, perception and action are essentially to be characterized as "conceptual and rational". Dreyfus maintains, by contrast, that some activity-particularly the fluent, embodied agency of the accomplished expert, or of everyday familiar coping, is not pervaded by mind at all. For if it were, then, according to Dreyfus, it would be reflective, and so distanced - and as such the agent would not be fully engrossed in the act itself. Dreyfus quotes a description of a soccer player by Merleau-Ponty, for whom the "field of forces" on the pitch are not a set of objective facts which are "given" to the player; but where on the contrary "the player becomes one with it (fait corps avec lui)" (Dreyfus 2013 citing Merleau-Ponty 1966, p. 168-169). So the Myth of the Pervasiveness of the Mental is, for Dreyfus, the view that all perception and action involves a kind of mental mirroring of the world, a view which, in Dreyfus's account, ignores the kind of absorbed coping in which mindfulness is absent.

McDowell counters this by attributing to Dreyfus a different myth - the "Myth of Mind as Detached". McDowell concedes that mind, on his view, involves rationality and conceptuality, stating that "rational mindedness pervades the lives of the rational animals we are, informing in particular our perceptual experience and our exercises of agency" (McDowell 2013, p. 41). However, such rationality and conceptuality does not need to be exercised by an agent through "a detached, contemplative relation to the world she experiences". Rather, reasons for acting, and thus conceptual framing of the action in the situation, have to be available to the agent as and when necessary, as a kind of inprinciple capacity that can be exercised if, for instance, she is asked "Why did you do that?" So, for McDowell, the kind of absorbed coping which is at the centre of Dreyfus's focus can indeed be accommodated within the former's view, because, McDowell says, not all mindedness is displayed as a detached, rational, reflection on an action: rationality will also be present merely as a cluster of unactualized conceptual capacities which come into play only as and when called for.

\subsection{Rationality and embodied-enactive suitedness}

In a recent commentary on this debate, Shaun Gallagher has suggested that much of what McDowell says can be accepted, even while maintaining the spirit of what Dreyfus incorporates into his picture of absorbed coping (Gallagher

\footnotetext{
${ }^{24}$ Dreyfus originally entitled this "the Myth of the Mental" but changed the title as it gave a misleading idea that dismissing the myth involved dismissing the existence of the mental as such, rather than a certain position, attributed by him to McDowell, concerning how mindedness related to action. (See Dreyfus 2007, 2013; McDowell 2007. For a later exchange, see, 2013; these, with other discussions in the debate, are collected in Schear 2013.)
}

2017, Sect. 10.3). Gallagher agrees with McDowell which, contra Dreyfus, there is a kind of rationality in those of our activities which embody absorbed coping. But, for Gallagher, this does not have to be the kind of intellectualized rationalization that he thinks McDowell sees as involved (in potentiality, though not necessarily in actuality) in relations between human mind and world. Gallagher thinks there is an alternative way to conceive rationality, namely as "an embodied-enactive practice" (Gallagher 2017, p. 200). The world that the agent relates to is a world of affordances or requirements: the kettle is something we can use to make coffee; the dishes in the sink are perceived as needing-tobe-washed, and so on. These affordances and requirements clearly are part of "the space of reasons". 25

As a development of this, Gallagher talks of the "rationality...implicit in the hand" (Gallagher 2017, p. 200, see also Chap. 9). As he says, if I reach out to grab a banana, the configuration of my hand is different depending on whether I am going to eat it myself or hand it to you to eat, or pretend it's a phone, or a gun. How my hand is shaped will differ for each of these cases - and these differences show, Gallagher says, how the way my hands (and, by extension, other parts of my body) shape themselves will display an "embodied, pragmatic rationality" which fits them into this or that situation in an appropriate manner.

The continually varying structure and dynamics of hand postures, crucial to musicians who use their hands to play their instruments, are of course illustrations par excellence of this rationality implicit in the hand-if, indeed, we follow Gallagher in talking of it in that way. We wish to question, however, whether the term "rationality" is being stretched too far here. It is true, as Gallagher goes on to point out, that hand gestures are intimately related with our linguistic communications: "The hand ... transforms its movements into language (via gesture) and into thinking". Indeed, human rational and conceptual capacities, as McDowell would agree, are closely bound up with our nature as language-using agents, and our use of language for thought and communication.

Hand gestures, and gestures and postures of many parts of the body, can indeed be used for thinking and for communicative acts in this way. And this is also true of many non-human species. ${ }^{26}$ However, if we were to extend such

\footnotetext{
$\overline{25}$ Thus Gallagher talks of a world that is "laid out in perception ... in terms of differentiations that concern my action possibilities-the object is something I can reach or not; something I can lift or not. .." (Gallagher 2017, p. 200).

${ }^{26}$ See (Hobaiter et al. 2014; Leavens et al. 2005) for how primates use their hands for pointing and other communicative acts. And of course dogs will pick up a lead in their mouth to indicate they want to be walked.
} 
enactive-embodied "rationality" to other species, it would frustrate an important objective in McDowell's philosophy, namely to use rationality as a way to characterize what differentiates human mindedness and agency from that of other creatures. So this may not be a path that Gallagher could easily induce McDowell to come along.

The notion of rationality plays a normative role in this discussion. For example, in explaining why I make a certain move in a chess game, I am exemplifying rationality in showing why the move was chosen as the right one given the situation on the board. But not all normativity in action has to be assimilable to rationality in that way. In executing a golf drive a player makes a set of movements that have a normative relation to the goals and situation. But, we suggest, this is not a rational normativity, but rather a kind of operative "suitedness," as it might be called. Such normative characterisations will fit the enactive-embodied account of agency that applies to much of what we do-including the kinds of absorbed coping which are at the heart of what is at issue between Dreyfus and McDowell. It would surely be better to avoid the use of the term "rationality" in this context, if only because of the strongly intellectualist connotations of the term. For this reason, we would prefer to talk in terms of embodied-enactive suitedness (or meetness or aptness) of an action within a given situation.

\subsection{Reflection in expert flow}

So far this would suggest that Dreyfus may be right in disputing the role played by notions such as rationality and conceptuality in McDowell's account of absorbed action in the flow. However, there is a certain tension in Dreyfus's account which Gallagher's discussion highlights well. Going back to the case of absorbed expert action in particular, it appears to be Dreyfus's view that the exercise of expert agency-in-flow is necessarily non-deliberate, non-reflective, and mindless. When discussing the case of an expert downhill skier, Gallagher points out that he may need "to reflectively consider changes in the texture of the snow, in order to anticipate possible adjustments to his skiing style" (Gallagher 2017, p. 201, footnote). This reflective thinking or monitoring would seem to be an integral part of the skier's expertise, yet it looks to be in conflict with Dreyfus's view that expert agency-in-flow is mindless and hence cannot contain elements of reflection. As reported by Gallagher (ibid), Dreyfus accepted this consequence (at a conference in 2006). Yet it seems a bizarre conclusion. When one executes a certain set of specialized skills one may often need to adopt a monitoring or quasi-reflective stance, alongside of, and integrated with, the operation of one's well-practised moves, in the flow of the skilled exercise.

In the present writers' experience as jazz players, this is particularly so for musical improvisation. Notwithstanding
Jason Rebello's remark (cited above) that thinking is often too "clunky" to do more than interfere with the flow of one's improvisation in the moment of performance, there are frequent cases where the musician employs forms of monitoring and observation during the performance. As we have elsewhere proposed in the skilled attention hypothesis (Clark et al. 2015), part of the skill of the accomplished performer is to integrate such monitoring processes seamlessly into the flow of the play. So an embodied-enactive account that is adequate to this kind of case will be one where (to use the language of Kahneman) system 1 and system 2 forms of operationality are woven together within the ongoing skilled performance. So skilled action-in-the flow is not necessarily mindless.

Indeed, a growing number of recent phenomenological discussions of this topic suggest a prominent role for mindfulness in real-world performance. For example, as with a skier's adjustment to the conditions of snow discussed by Gallagher (above), Sutton et al. observe that elite cricket players adjust their batting to hit a shot through a slim gap in the field, where the action is fast enough for it to be like a reflex, but nevertheless is context-sensitive in a way that actions requires mindfulness about the in-the-moment disposition of the players (Sutton et al. 2011, p. 80). Similarly, for basketball players, rather than leading to "choking" (Beilock and Carr 2001; Cappuccio 2017), it is important that they pay deliberate attention to their dribbling of the ball at just the right moments in the play (Montero 2016, p. 100). In a related way, chefs, despite a perception of their cooking as driven by feelings of "this has to be there, this feels right here", also report the importance of never ceasing to learn; and as Bermúdez points out, there would be no possibility of learning if "the mind is shut off during performance" (Bermúdez 2017, p. 2).

\subsection{Playing with intention}

Reports in the domain of musical performance in particular highlight a further function of mindfulness beyond such context sensitivity that we see as central, but that is left out so far. This is the role of mindfulness in forming (spontaneous) action that is intentional and goal-directed. Many classical performers stress the importance of directing musical performance with a clarity of intention, and see it as a mistake and a myth that a mindless performance in-the-moment should be what leads the music (as Dreyfus suggests). For cellist Ingal Segev, such elimination of thought in the performance also eliminates the playing as driven by the artist's ongoing conception or image of the music as it unfolds in time, based, as it is, on copious prior study and practice (Montero 2016, p. 100). Heinrich Neuhaus, the teacher of classical pianist Sviatoslav Richter and author of what is considered one of the most authoritative books on piano pedagogy, The 
Art of Piano Playing (Neuhaus 1967), even links the success of gifted students such as Richter to the clearest formation and expression of the musical-artistic intention. To Neuhaus, work on the artistic image ("Arbeit am künstlerischen Bild") is of the utmost importance, since a lack of awareness of the musical intention leads to a performance that does not express the character of the music, but evokes "instead of the language a murmuring, instead of a clear thought meagre rips of it, instead of a strong feeling powerless efforts, instead of the deeper logic 'consequences without causes', instead of poetic images their prosaic leftovers" ${ }^{27}$ (Neuhaus 1967 , p. 1). As we shall see below, given the importance of playing within a musical language, a form of mindful embodied-enactive suitedness, allowing for meaningful intentional action within the domain of music, is perhaps even more central to the improviser's efforts to spontaneous musical creation.

In a similar way, Høffding's interviews with the Danish String Quartet point to a role for kinds of mindful reflection at varying levels of agency in the performance. Høffding comes to view absorption in musical performance (as targeted in Dreyfus's account) more as a "passiveness" about certain aspects of the performance than as a "mindlessness" in the performance (Høffding 2014; Salice et al. 2017). This is seen as resulting from a control of the instrument as a tool that is temporarily integrated into the body schema, so that many details of the instrument can be forgotten (see also Schiavio and De Jaegher 2017, for a notion of "incorporated control" by the musician of her instrument). Høffding goes on to say, however, that body schematic control over an instrument does not imply a mindless control of the music. Beyond a body-schematic instrumental control, musicians have to exercise agency on various levels of the musical performance proper, including that of the music itself, but also, for example, the affective connotations of the playing, and their interactions with other musicians.

\subsection{An improviser's innards}

In what follows we take this last point on agency within the domain of music a little further, with implications on the nature of an improviser's skills. In line with the role of mindfulness for the music itself, David Sudnow's phenomenological analysis of his own path towards becoming a proficient improviser (Sudnow 1978) suggests that, as expert musicians and improvisers achieve a transparent control over their instrument, they do not enter a stage where their

\footnotetext{
27 Translated by the authors from the German edition, in which this passage reads as: "anstelle der Sprache kam ein Gemurmel heraus, anstelle des klaren Gedankens kärgliche Fetzen eines solchen, anstelle eines starken Gefühls kraftlose Bemühungen, anstelle der tiefen Logik 'Folgen ohne Ursachen', anstelle poetischer Bilder ihre prosaischen Reste." (Neuhaus 1967, p. 1).
}

playing reduces to an absorbed mindless coping. Rather, expert musicians, and improvisers in particular, gain an ability to achieve an embodied-enactive suitedness or aptness (as we have called it) in their playing, that allows them to act with high-level agency on the music itself. In doing so, they come not to fully disappear in, but rather to express themselves via, musical utterings. From this angle, we perceive one weakness in Dreyfus' view of absorbed coping - at least with respect to improvisation-to be that he seems to assume a pre-given domain that is rendered mindless once it is mastered. However, we suggest that alongside the notion of performance-in-the-flow elaborated by Dreyfus, there has to be emphasized a never-ending developmental aspect of enactive creation. In improvisation one is, as in learning, faced with a certain "breakdown" of one's habitual skills in continually occurring novel constraints from the interaction with the world (Di Paolo et al. 2014). So a sense-maker must, to some degree, continuously engage with new situations she has not until now come to perceive or act in. This creates an (for her, previously non-existent) aptness and normativity concerning how to walk the very walk she is walking, or (for the music improviser) the music she is playing. ${ }^{28}$

Sudnow provides vivid reports of such continuous experiential "appearances" or "openings" of co-developing normativity and aptness (see, for example, Sudnow 2001, p. 77; the terminology is not his). In setting out to learn how to improvise music, he depicts his initial perception of the piano as purely visual-spatial, significant only in terms of successful reaches for certain keys in space; but much of the book is about how, during this path, he bears witness to a continuous bringing-forth of novel, and eventually musical, experiential relations with his instrument. Once he had sufficiently mastered the visual-spatial world, he came to enter a world of sound in which he was concerned not so much with the pressing of the keys, as with the formation of direct intentions within the musical domain.

Such a first foundational transition in his experiential relation with the piano was marked when for the first time he began to feel "expressly aiming for the sound of [a] particular note, that the sounds seemed to creep up into my fingers, that the depression of the keys realized a sound being prepared on the way down, that I had gone to do them" (Sudnow 1978, p. 37). He was now not any more "going for good places ... [but] aiming for sounding spots" (ibid). Multiple further cases of such experientially transformative shifts occurred during his learning, described in great detail, when, beyond a world of sound, Sudnow came to create for

\footnotetext{
${ }^{28}$ Di Paolo et. al's adaptation of Piaget's concept of equilibration for an enactive theory of perceptual learning explicitly addresses the "open-ended nature of human learning" (Di Paolo et al. 2014, p. 1), and points also to the need for an agent's "intrinsic normative evaluation" (ibid) for such learning.
} 
himself the worlds of (and aptness for) melodies (p. $38 \mathrm{ff}$ ), harmonies (p. $50 \mathrm{ff}$ ), and rhythms and phrasings (p. $81 \mathrm{ff}$ ). Each of these neither emerged as complete, nor as globally available, nor in a single moment, but rather, as with other forms of enactive perceptual sensorimotor learning, ${ }^{29}$ in a continuous locally-contextual unfolding, yielding one additionally gained way of knowing and then another-until, much later, he could express himself more globally in a way he saw as being intentional and meaningful in a language of jazz.

This aspect of Sudnow's account particularly reverberates with the present authors' experience as jazz players. Given such an account, we think Sudnow's path renders a view on mastery and expertise that actually diverges from that advanced by Dreyfus. Attaining aptness in the control over one or another aspect of his developing craft did not render Sudnow's improvisatory playing mindless, but rather enriched it with novel features, musical objects and contextually appropriate novel ways for musical enacting. And as Sudnow reports (along with other experts), this process seems to be an indefinite one. However, Dreyfus's account seems to be one that implies that an expert will approach a summit, where the performance is rendered mindless. In contrast, we argue that a better view is one of continual exploration and perfection-especially for peak improvisers. Enacting novel worlds never ends.

Thus we arrive at a somewhat different conclusion than that offered by Dreyfus himself about Sudnow's account. For Dreyfus, Sudnow's journey towards improvisation "reaches its climax, [when] there is finally no longer an I that plans, not even a mind that aims ahead, but a jazz hand that knows at each moment how to reach for the music." [See Dreyfus's foreword to (Sudnow 2001), p. x]. However while Sudnow does talk of his hand to coming to "know" and gaining a "potential for musical action", his account does not appear to imply that one's mind goes fully blank in absorbed coping as one comes to master "musical reaching" in improvisation. Rather, Sudnow's account illustrates the open-ended path of enactive perceptual learning that continues to create novel objects and, eventually, novel experiential domains (Di Paolo et al. 2014).

A key claim we wish to make here, then, is that in improvisation, in addition to a basis in open-ended perceptual learning, also the formation of novel intentions for action is open-ended; and that spontaneously creating novel forms of agentive goal-directedness lies at the heart of improvisation-and, indeed, of life. The improvising mind enacts a form of hierarchical higher-level sense-making over the possible perceptions of the moment, as well as over the possible sensory-motor schemes available for action in the now. At

${ }^{29}$ See (Di Paolo et al. 2014) for an enactive theory of perceptual learning. its highest level, this may be seen as a form of "inner sensemaking" that flexibly creates novel intentions in the present moment. A making-sense not only of the external world but also of the realm of potentially available actions and their expected consequences, creating (or "finding") in real time novel ways of "intending". This may be what pianist Bill Evans refers to when saying - quoted at the beginning of the paper-that "direct deed is the most meaningful reflection" (Evans 1959, emphasis added). In this, the improvising mind goes beyond an expert's mindful monitoring of a pre-given course of action, that intends to execute a pre-given image that was formed during (often extensive) prior practice. One might perhaps say that expertise is more an endeavour of sense-exploitation or sense-remaking, while improvisation is, rather, an activity of in-the-moment sense-making, or sense-exploration.

This is, obviously, not to suggest, simplistically, that improvisation is essentially free, and that expert recitative performance is essentially constrained. Each occupy different regions on a constraint-freedom continuum that may be seen as underlying spontaneous thought and action (Christoff et al. 2016). An expert recitative performer, residing towards the more constrained end of the spectrum, has choices of direct action that are more familiar. The recitalist is, in performance, re-telling a story that is already composed and written, even though such performers may aim to tell the story as if it were for the first time. On the other hand, the expert improviser, residing at the more unconstrained end of the spectrum, has prepared (in equally extensive prior practice) a large number of directly available choices of action with which, within the performance, she seeks to tell a narrative that is composed as it unfolds.

So, we suggest, the cognitive process of improvisation in jazz - and in life-can be conceived of as a form of inner sense-making, an explorative higher-level making-sense of the direct possibilities of what the situation could be made into. Such making-sense of the inner domain of possibilities for meaningful (musical) perception and action and their respective consequences creates a novel perception (or intention) about what the situation should be made into.

In this way, we suggest, the expert player is not someone who is mindlessly absorbed, as in Dreyfus's account, but rather one who gets to aptly express her self in continually novel ways (small or more drastic). Consequently, in place of Dreyfus's picture of the ego-less, absorbed expert improviser who is without an "I that plans", we have an improviser whose acts are the spontaneous expression of herself. This, we believe, is how best to recast-or extendDreyfus's account of the absorbed expert, through the lens of improvisation. 


\section{Summing up}

This paper takes as its focal centre of interest the world of the improvising jazz musician. It draws upon the background of the authors, both of whom have some practical experience of playing jazz (but more importantly, a deep admiration of the real experts in the art). Inspired by Sudnow's Ways of the Hand, our shared interest in the phenomenology of jazz, and the exploration of its practice, has led us to reflect on the jazz player's improvisatory expertise. Improvisation in performance art, and the expertise of the in-the-moment creator, provides a rich canvas from which to explore the nature of improvisation and expertise more generally within our daily lifeworld.

The assertion that improvisatory behaviour is ubiquitous within everyday life appears as both unsettling and banal. Banal because, once it is expressed, it seems too obvious to make much of (but we question that). And it is unsettling because of the apparent lack of serious work, within the mind sciences and philosophy, on the nature of improvisation, and on how the latter contrasts with non-improvised behaviour. How might the field be different if improvisation had a more central place? We have made some inroads here on this, and we have mentioned some valuable work by others, for example, the suggestion that the phrase $4 \mathrm{E}$ be extended with an additional I for "improvised" (or a fifth E for "extemporised"); but there is a vast territory to be worked on.

In the first part of the present paper, we have explored the activity of improvisation against the theoretical backdrop of work by Dreyfus and other authors. Dreyfus is celebrated as a forthright critic of the limitations of the cognitivist approach to mind (both artificial and natural). Enactivism has strong links to Dreyfus's work, sharing roots in continental phenomenology, and an anti-cognitivist stance. We have suggested ways in which enactivism also provides a rich source of insights on improvisation-for example-through its central notion of "sense-making", but also other notions.

Since improvisation is essentially a form of creation in the moment (the creativity often spurred by the moment), we thought it important to articulate some of the ways in which temporality is crucially bound up with improvisation in a mesh of different time scales, both as an artistic discipline and as a daily practice. We cite the affirmations of several jazz musicians about their work, which bear testimony to this. This opens up another rich seam to be explored further, both in relation to jazz and other improvisatory art, and in a broader context.

In the second part of the paper, we turned our attention to the cognitive processes behind an improvising musician's expertise. Dreyfus has been a, or the, major contributor to our understanding of the nature of expertise. The debate between Dreyfus and the AI community has been particularly instructive in terms of understanding the limitations and potential of artificial cognitive systems for reproducing aspects of human expertise. But we have focused on another, more recent, related debate engaged in by Dreyfus (principally with John McDowell): the role of mind or ego in the activity of the fully proficient expert. Dreyfus takes the flow of the accomplished expert, or the virtuoso performer, in art and in sport, for example, to be a mindless flow-and so, too, for one's "absorbed coping" in other, less lofty, achievements. Although Dreyfus appears rarely to focus specifically on improvisation in the relation to absorbed coping, his views are of particular relevance in that area. We have challenged his claim that expert performance in-the-moment, in particular if improvised, is mindless or egoless.

Looking at observations by McDowell, Gallagher, Sudnow, and several other writers, we have concluded (as have others) that the Dreyfusian account has to be carefully rewritten, or extended. In our own distinctive account (which applies particularly to the case of improvisation, but which may have more general application), we suggest that expert improvisers do not enter a stage of absorbed mindless coping, but are instead on a path of open-ended expansion (and sometimes transformation) of their mindful experiential relation with their doing. For instance, a player's engagement with the piano's keys may unify with the piano's sound, until she becomes habituated to perceive and act with direct, nondeliberative, intentional agency on musical features such as melodies, the form of the flow, the affective connotations of the playing, and so on.

We propose that at the heart of an improviser's expertise (and indeed, of day-to-day living) lies the spontaneous creation of novel forms of agentive goal-directedness. Both drawing on, and extending, enactive theory, we suggest that such improvisatory ability is grounded in a form of "higherlevel inner sense-making" that operates in the moment over a rich realm of perceptual relations and sensory-motor schemes that have been established in prior practice. By this, summing up, we supplant Dreyfus's idea of the egoless absorbed expert, as applied to improvisation, by that of an mindful (i.e. present in the moment) improviser enacting spontaneous expressions of herself.

Acknowledgements We would like to thank two anonymous reviewers for their insightful comments; as well as audience members in London, Bristol and Sussex for giving us the opportunity to allow our ideas to grow, and for providing us with a wealth of useful insights. Further, we are grateful to a number of people, from whom we have had fruitful contacts of a theoretical and/or musical nature, in relation to the present paper. These include: Christian Artmann, Alan Bern, Chris Biscoe, Ron Chrisley, Andy Clark, Dav Clark, Hanne De Jaegher, Ezequiel Di Paolo, Madeline Drake, Tom Froese, David Germano, Laszlo Gardony, Shaun Gallagher, Jeff Haller, Anna Jordanous, Adam Linson, Lynn McDonald, Heinz Muntz, Kevin O’Regan, Jason Rebello, David Silverman, Dan Tepfer, Arist von Schlippe, Peter Wilson. FS was supported by ERC Advanced Grant 323674 "FEEL" to J. Kevin O'Regan and by ERC Advanced Grant DLV-692739 “XSPECT" to Andy Clark. 
Open Access This article is distributed under the terms of the Creative Commons Attribution 4.0 International License (http://creativeco mmons.org/licenses/by/4.0/), which permits unrestricted use, distribution, and reproduction in any medium, provided you give appropriate credit to the original author(s) and the source, provide a link to the Creative Commons license, and indicate if changes were made.

\section{References}

A Passion for Jazz: Music History and Education (2017). https://www. apassion4jazz.net. Accessed 2 Dec 2017

Agre PE (1988) The dynamic structure of everyday life. AI technical report 1085. http://hdl.handle.net/1721.1/6975. Accessed 2 Dec 2017

Agre PE, Chapman D (1987) Pengi: AN implementation of a theory of activity. In: Proceedings of the sixth national conference on artificial intelligence, vol 278, pp. 268-272. Seattle, Washington. http://www.aaai.org/Library/AAAI/1987/aaai87-048.php. Accessed 2 Dec 2017

Beilock SL, Carr TH (2001) On the fragility of skilled performance: what governs choking under pressure? J Exp Psychol Gen 130(4):701-725

Beilock SL, Carr TH (2004) From novice to expert performance: attention, memory, and the control of complex sensorimotor skills. Skill Acquis Sport Res Theory Pract 1967:309-328

Berendt JE (1982) The Jazz book-from ragtime to fusion and beyond. Lawrence Hill Books, Chicago

Bermúdez JP (2017) Do we reflect while performing skillful actions? Automaticity, control, and the perils of distraction. Philos Psychol 30(7):896-924. https://doi.org/10.1080/09515089.2017.1325457

Bowman W (2004) Cognition and the body: perspectives from music education, pp 29-50. https://doi.org/10.1007/978-1-4020-2023-0_3

Brown C (2015) We're playing classical music all wrong-composers wanted us to improvise. The Conversation, pp 19-21. http://theco nversation.com/were-playing-classical-music-all-wrong-compo sers-wanted-us-to-improvise-36090. Accessed 14 Jan 2015

Cappuccio M (2017) Flow, choke, skill. In: Radman Z (ed) Before consciousness: in search of the fundamentals of mind, pp 246-283. Imprint Academic, Exeter

Cavrell L (1966) The universal mind of Bill Evans: the creative process and self-teaching [video flim]. Hal Leonard Publishing Corporation. https://www.youtube.com/watch? $\mathrm{v}=\mathrm{ie} 3 \mathrm{sglFcum} 4 \&$ spfre load=10. Accessed 2 Dec 2017

Cheadle D (2015) Miles ahead [Video file]. Legacy Recordings. https ://www.facebook.com/LegacyRecordings/videos/1015401304 $1127996 /$

Christoff K, Irving ZC, Fox KCR, Spreng RN, Andrews-Hanna JR (2016) Mind-wandering as spontaneous thought: a dynamic framework. Nat Rev Neurosci 17(11):718-731. https://doi. org/10.1038/nrn.2016.113

Clark D, Schumann F, Mostofsky SH (2015) Mindful movement and skilled attention. Front Hum Neurosci 9:1-23. https://doi. org/10.3389/fnhum.2015.00297

Colombetti G, Torrance S (2009) Emotion and ethics: an inter-(en) active approach. Phenomenol Cogn Sci 8(4):505-526. https://doi. org/10.1007/s11097-009-9137-3

Corea C (2016) Improvisation piano exercises from chick corea [Video file]. https://www.youtube.com/watch?v=yfoxdFHG7Cw

Daniel K (2011) Thinking fast and slow. Allen Lane, London https:// doi.org/10.1007/s13398-014-0173-7.2

Davis M, Evans B, Cobb J, Chambers P, Coltrane J, Adderley J, Kelly W (1959) Kind of Blue. Columbia Records. https://de.wikipedia. org/wiki/Kind_of_Blue
De Jaegher H, Di Paolo E (2007) Participatory sense-making: an enactive approach to social cognition. Phenomenol Cogn Sci 6(4):485507. https://doi.org/10.1007/s11097-007-9076-9

Di Paolo EA, Barandiaran XE, Beaton M, Buhrmann T (2014) Learning to perceive in the sensorimotor approach: Piaget's theory of equilibration interpreted dynamically. Front Hum Neurosci 8:116. https://doi.org/10.3389/fnhum.2014.00551

Dietrich A (2004) Neurocognitive mechanisms underlying the experience of flow. Conscious Cogn 13(4):746-761. https://doi. org/10.1016/j.concog.2004.07.002

Dreyfus HL (1972) What computers can't do. MIT Press, New York

Dreyfus HL (2005) Peripheral vision: expertise in real world contexts. Org Stud. https://doi.org/10.1177/0170840605053102

Dreyfus HL (2007) The return of the myth of the mental. Inquiry 50(4):352-365

Dreyfus HL (2013) The myth of the pervasiveness of the mental. In: Schear JK (ed) Mind, reason, and being-in-the-world: the mcdowell-dreyfus debate. Routledge, New York, pp 1-40

Dreyfus HL, Dreyfus SE (1986) Mind over machine: the power of human intuition and expertise in the era of the computer. Blackwell, Oxford

Ericsson KA, Krampe RT, Tesch-Römer C (1993) The role of deliberate practice in the acquisition of expert performance. Psychol Rev 100(3):363-406. https://doi.org/10.1037/0033-295X.100.3.363

Evans B (1959) Liner notes to Miles Davis "Kind of Blue". Columbia Records. https://de.wikipedia.org/wiki/Kind_of_Blue

Gallagher S (2017) Enactivist Interventions: rethinking the mind. Oxford University Press, Oxford

Goldman A (2013) Towards a cognitive-scientific research program for improvisation: theory and an experiment. Psychomusicol Music Mind Brain 23(4):210-221. https://doi.org/10.1037/pmu0000020

Hendriks-Jansen H (1996) Catching ourselves in the act: situated activity, interactive emergence, evolution, and human thought. MIT Press, Cambridge

Higgins L, Mantie R (2013) Improvisation as ability, culture, and experience. Music Educ J 100(2):38-44. https://doi.org/10.1177/00274 32113498097

Hobaiter C, Leavens DA, Byrne RW (2014) Deictic gesturing in wild chimpanzees (Pan troglodytes)? Some possible cases. J Comp Psychol 128(1):82-87. https://doi.org/10.1037/a0033757

Høffding S (2014) What is skilled coping?: experts on expertise. J Conscious Stud 21(9-10):49-73

Ikeda D, Hancock H, Shorter W (2006) The music of eternal life. Soul freedom: jazz, life and Buddhism. Seikyo Shimbun, Shinjuku

Iyer V (2004) Improvisation, temporality and embodied experience. J Conscious Stud 11(3):159-173

Johnstone K (1979) Impro-improvisation and the theatre. Methuen Publishing, London

Jordanous A, Keller B (2012) What makes musical improvisation creative ? J Interdiscip Music Stud 6(2):151-175. https://doi. org/10.4407/jims.2014.02.003

Krueger JW (2011) Doing things with music. Phenomenol Cogn Sci 10(1):1-22. https://doi.org/10.1007/s11097-010-9152-4

Krueger J (2014) Affordances and the musically extended mind. Front Psychol 4:1-13. https://doi.org/10.3389/fpsyg.2013.01003

Laroche J, Kaddouch I (2014) Enacting teaching and learning in the interaction process: "Keys" for developing skills in piano lessons through four-hand improvisations. J Pedag 5(1):24-47. https://doi. org/10.2478/jped-2014-0002

Laroche J, Berardi AM, Brangier E (2014) Embodiment of intersubjective time: relational dynamics as attractors in the temporal coordination of interpersonal behaviors and experiences. Front Psychol 5:1-17. https://doi.org/10.3389/fpsyg.2014.01180

Leavens DA, Hopkins WD, Bard KA (2005) Understanding the point of chimpanzee pointing. Curr Dir Psychol Sci 14(4):185-189. https ://doi.org/10.1111/j.0963-7214.2005.00361.x 
Lewis GE (2009) The condition of improvisation. International Society for Improvised Music, Santa Cruz

Linson A, Clarke EF (2017) Distributed cognition, ecological theory and group improvisation. In: Clarke EF, Doffman M (eds) Distributed creativity: collaboration and improvisation in contemporary music. Oxford University Press, New York, pp 52-69

Linson A, Dobbyn C, Lewis GE, Robin L (2015) A subsumption agent for collaborative free improvisation. Comput Music J 39(4):96115. https://doi.org/10.1162/COMJ

Loaiza J (2016) Musicking, embodiment and participatory enaction of music: outline and key points. Connect Sci. https://doi. org/10.1080/09540091.2016.1236366

Machado A (1912) Proverbios y cantares XIX, in Machado A (1912) Campos de Castilla. Madrid 1912

Maturana HR, Varela FJ (1986) The tree of knowledge: a new look at the biological roots of human understanding. New Science Library, Boston

Matyja J, Shiavio A (2013) Enactive music cognition: background and research themes. Constructivist Foundations 8(3):351-357

Merleau-Ponty M (1966) Structure of Behavior. 2nd edn. Beacon Press, Boston

McDowell JJ (2007) What myth? Inquiry 50(4):338-351

McDowell JJ (2013) The myth of the mind as detached. In: Schear JK (ed) Mind, reason, and being-in-the-world: the mcdowell-dreyfus debate, pp 41-58, New York

Menary R (2010) Introduction to the special issue on $4 \mathrm{E}$ cognition. Phenomenol Cogn Sci 9(4):459-463. https://doi.org/10.1007/ s11097-010-9187-6

Mercer M (2007) Footprints: the life and work of Wayne shorter. TarcherPerigee, New York

Milka A (2015) Quaerendo invenietis in J. S Bach' s Musical Offering BWV 1079. Min-Ad: Israel Studies in Musicology Online, 13(1954), pp 46-50. https://www.biu.ac.il/hu/mu/min-ad/1516/04Milka.pdf. Accessed 2 Dec 2017

Miller D, Iyer V (2010) Improvising digital culture: a conversation. Crit Stud Improv 5(1):1-10

Montero B (2016) Thought in action. Oxford University Press, Oxford Nachmanovitch S (1990) Free play: Improvisation in life and art. Tarcher/Perigee, New York

Neuhaus H (1967) Die Kunst des Klavierspiels. edition ge. Köln: Musikverlage Hans Gerig

Newen A, de Bruin L, Gallagher S (eds) (Forthcoming) The Oxford handbook of 4E cognition. Oxford University Press, Oxford

NYU Steinhardt Jazz Studies (2014) Conversations with Wayne shorter-episode I [video file]. https://www.youtube.com/watch $? \mathrm{v}=$ Dzx 9scGdrGA\&t=11s. Accessed 2 Dec 2017

Oudeyer PY, Smith LB (2016) How evolution may work through curiosity-driven developmental process. Topics Cogn Sci 8(2):492502. https://doi.org/10.1111/tops.12196

Rowlands M (2010) The mind embodied, embedded, enacted and extended. In: Rowlands $M$ (ed) The new science of the mind: from extended mind to embodied phenomenology, pp 51-84. MIT Press, Cambridge

Salice A, Høffding S, Gallagher S (2017) Putting plural self-awareness into practice: the phenomenology of expert musicianship. Topoi. https://doi.org/10.1007/s11245-017-9451-2

Schear JK (2013) Mind, reason, and being-in-the-world: the McDowell-Dreyfus debate. Routledge, New York

Schiavio A (2014) Action, enaction, inter(en)action. A commentary on Leman and Maes, "The role of embodiment in the perception of music.” Empir Musicol Rev 9(3-4):254-262

Schiavio A, Cummins F (2015) An inter(en)active approach to musical agency and learning. In: Timmers R, Dibben N, Eitan Z, Granot R, Metcalfe T, Schiavio A, Williamson V (eds) Proceedings of ICMEM 2015. International Conference on the Multimodal Experience of Music, pp. 1-12. HRI Online Publications, Sheffield.
https://www.hrionline.ac.uk/openbook/chapter/ICMEM2015Schiavio. Accessed 2 Dec 2017

Schiavio A, De Jaegher H (2017) Participatory sense-making in joint musical practice. In: Lesaffre M, Leman M, Maes PJ (eds) The Routledge companion to embodied music interaction, pp 31-139. Routledge, Abingdon

Schiavio A, Menin D, Matyja J (2014) Music in the flesh: embodied simulation in musical understanding. Psychomusicol Music Mind Brain 24(3):340-343. https://doi.org/10.1037/pmu0000052

Schiavio A, van der Schyff D, Cespedes-Guevara J, Reybrouck M (2017) Enacting musical emotions. sense-making, dynamic systems, and the embodied mind. Phenomenol Cogn Sci 16(5):785809. https://doi.org/10.1007/s11097-016-9477-8

Spencer JP, Clearfield M, Corbetta D, Ulrich B, Buchanan P, Schöner G (2006) Moving toward a grand theory of development: in memory of Esther Thelen. Child Dev 77(6):1521-1538. https://doi.org/10. 1111/j.1467-8624.2006.00955.x

Stanovich K (2011) Rationality and the reflective mind. Oxford University Press, Oxford

Sudnow D (1967) Passing on: the social organisation of dying. Prentice-Hall, Upper Saddle

Sudnow D (1978) Ways of the hand. Havard University Press, Cambridge

Sudnow D (1979) Pilgrim in the microworld. Grand Central Publishing, New York

Sudnow D (2001) Ways of the hand-a rewritten account, vol 1. MIT Press, Cambridge. https://doi.org/10.1017/CBO978110741532 4.004

Sutton J, McIlwain D, Christensen W, Geeves A (2011) Applying intelligence to the reflexes: embodied skills and habits between dreyfus and descartes. J Br Soc Phenomenol 42(1):78-103. https://doi. org/10.1080/00071773.2011.11006732

Thelen E, Smith LB (1994) A dynamic systems approach to the development of cognition and action. MIT Press, Cambridge

Thompson E (2007) Mind in life: biology, phenomenology, and the sciences of mind. Harvard University Press, Cambridge

Tomasello M (2014) A natural history of human thinking. Havard University Press, Cambridge

Torrance S, Froese T (2011) An inter-enactive approach to agency: participatory sense-making, dynamics, and sociality. Humana Mente 15:21-54

van der Schyff D (2017) Improvisation, enaction and self-assessment. In: David J, Elliott; M, Silverman, McPherson G (eds) The Oxford handbook of philosophical and qualitative perspectives on assessment in music education, pp 1-25

van der Schyff D, Schiavio A (2015) The embodied musical mind: enactive cognitive science and music education. In: Symposium International LTM21/AEM2, Montreal

Varela FJ (1984) Living ways of sense-making: a middle path for neuroscience. In: Livingstone $\mathrm{P}$ (ed) Order and disorder: proceedings of the stanford international symposium, pp. 208-224. Anma Libri, Stanford

Varela FJ (1987) Laying down a path in walking: a biologist's look at a new biology. Cybernetic 2:6-15

Varela FJ, Thompson E, Rosch E (1991) The embodied mind: cognitive science and human experience. MIT Press, Cambridge

Walton AE, Richardson MJ, Langland-Hassan P, Chemero A (2015) Improvisation and the self-organization of multiple musical bodies. Front Psychol 6:1-9. https://doi.org/10.3389/fpsyg .2015 .00313

Werner K (1996) Effortless mastery. Jamey Aebersold, New Albany

Winograd T, Flores F (1986) Understanding computers and cognition: a new foundation for design. Ablex Publishing Corporation, Norwood 